\title{
DK-iteration robust control design of a wind turbine
}

\author{
Mirzaei, Mahmood; Niemann, Hans Henrik; Poulsen, Niels Kjølstad
}

Published in:

2011 IEEE International Conference on Control Applications

Link to article, DOI:

10.1109/CCA.2011.6044429

Publication date:

2011

Document Version

Publisher's PDF, also known as Version of record

Link back to DTU Orbit

Citation (APA):

Mirzaei, M., Niemann, H. H., \& Poulsen, N. K. (2011). DK-iteration robust control design of a wind turbine. In 2011 IEEE International Conference on Control Applications IEEE. https://doi.org/10.1109/CCA.2011.6044429

\section{General rights}

Copyright and moral rights for the publications made accessible in the public portal are retained by the authors and/or other copyright owners and it is a condition of accessing publications that users recognise and abide by the legal requirements associated with these rights.

- Users may download and print one copy of any publication from the public portal for the purpose of private study or research.

- You may not further distribute the material or use it for any profit-making activity or commercial gain

- You may freely distribute the URL identifying the publication in the public portal

If you believe that this document breaches copyright please contact us providing details, and we will remove access to the work immediately and investigate your claim. 


\title{
$D K$-Iteration Robust Control Design of a Wind Turbine
}

\author{
Mahmood Mirzaei, Hans Henrik Niemann and Niels Kjølstad Poulsen
}

\begin{abstract}
The problem of robust control of a wind turbine is considered in this paper. A controller is designed based on a 2 degrees of freedom linearized model. An extended Kalman filter is used to estimate effective wind speed and the estimated wind speed is used to find the operating point of the wind turbine. Due to imprecise wind speed estimation, uncertainty in the obtained linear model is considered. Uncertainties in the drivetrain stiffness and damping parameters are also considered as these values are lumped parameters of a distributed system and therefore they include inherent uncertainties. We include these uncertainties as parametric uncertainties in the model and design a robust controller using $D K$-iteration method. The controller is applied on a full complexity simulation model and simulations are performed for wind speed step changes.
\end{abstract}

\section{INTRODUCTION}

There is an increasing interest in wind energy and wind turbines are the most common wind energy conversion systems (WECS). Control is an essential part of the wind turbine system because control methods can decrease the cost of energy by increasing the power capture by keeping the turbine close to its maximum efficiency and also by reducing structural loadings and therefore increasing lifetime of the wind turbine. Wind turbines essentially have two regions of operation, partial load and full load. In the partial load wind speed is not fast enough to produce rated power. In this region the main control objective is to track the maximum power coefficient $\left(C_{P \max }\right)$ and extract as much power as possible. Pitch is mostly fixed in this region and generator reaction torque is adjusted to control rotational speed and keep the operating point close to $C_{P \max }$. In the full load region wind speed is above rated and wind power exceeds rated power of the generator, therefore by decreasing aerodynamics efficiency of the rotor we try to control the captured power and this is done by pitching the blades. There are several methods for wind turbine control ranging from classical control methods [1] which are the most used method in real applications to advanced and model based control methods which have been the focus of research in the past few years [2]. Gain scheduling [3], adaptive control [4], time invariant MIMO methods [5], nonlinear control [6], robust control [7], model predictive

This work is supported by the CASED Project funded by grant DSF-09063197 of the Danish Council for Strategic Research

M. Mirzaei is with department of Informatics and Mathematical Modeling, Technical University of Denmark, 2800 Kongens Lyngby, Denmark mmireimm.dtu.dk

H. H. Niemann is with department of Electrical Engineering, Technical University of Denmark, 2800 Kongens Lyngby, Denmark hhn@elektro.dtu.dk

N. K. Poulsen is with department of Informatics and Mathematical Modeling, Technical University of Denmark, 2800 Kongens Lyngby, Denmark $n k p @ i m m \cdot d t u \cdot d k$

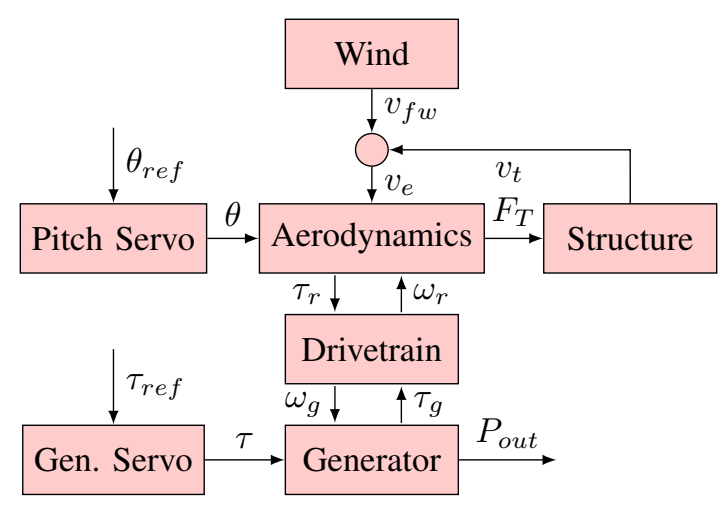

Fig. 1: Wind turbine subsystems

control [8] are to mention a few. Advanced control methods are thought to be the future of wind turbine control as they can employ new generations of sensors on wind turbines (e.g. LIDAR [9]), new generation of actuators (e.g. trailing edge flaps [10]) and also conveniently treat the turbine as a MIMO system. The last feature seems to become more important than before as wind turbines become bigger and more flexible which make decoupling different modes and designing controller for each mode more difficult. The wind turbine in this paper is treated as a MIMO system with pitch reference $\left(\theta_{r e f}\right)$ and generator reaction torque $\left(Q_{r e f}\right)$ as inputs and rotor rotational speed $\left(\omega_{r}\right)$, generator rotational $\operatorname{speed}\left(\omega_{g}\right)$ and generated power $\left(P_{e}\right)$ as outputs. This paper is organized as follows: In the section II modeling of the wind turbine including modeling for wind speed estimation, linearization and uncertainty modeling is addressed. In the section III-A controller design is explain and in the section IV robust performance problems is addressed. And finally in the section $\mathrm{V}$ simulation results are presented.

\section{Modeling OF THE Wind TURBine}

For modeling purposes, the whole wind turbine can be divided into 4 subsystems: Aerodynamics subsystem, structural subsystem, electrical subsystem and actuator subsystem. Figure 1 shows the basic subsystems and their interactions. The dominant dynamics of the wind turbine come from its flexible structure. Several degrees of freedom could be considered to model the flexible structure, but for control design mostly just a few important degrees of freedom are considered. Mostly the degrees of freedom whose eigen frequncies lie inside actuator bandwidth are considered otherwise including them into the design model is useless and makes the design model unnecessarily complicated. In this work we only consider two degrees of freedom, 
namely the rotational degree of freedom(DOF) and drivetrain torsion. The aerodynamics subsystem in the model gets effective wind $\operatorname{speed}\left(v_{e}\right)$, pitch angle $(\theta)$ and rotational speed of the $\operatorname{rotor}\left(\omega_{r}\right)$ and returns aerodynamic torque $\left(T_{r}\right)$ and $\operatorname{thrust}\left(F_{T}\right)$. This subsystem is responsible for the nonlinearity in the wind turbine model. More details are presented in the section II-B.

\section{A. Wind Model}

Wind model can be modeled as a complicated nonlinear stochastic process, however for practical purposes it could be approximated based on a linear model. In this model the wind has two elements, mean value term $\left(v_{m}\right)$ and turbulent $\operatorname{term}\left(v_{t}\right)$ :

$$
v_{e}=v_{m}+v_{t}
$$

The turbulent term could be modeled by the following state space model:

$$
\begin{aligned}
{\left[\begin{array}{c}
\dot{v}_{t} \\
\ddot{v}_{t}
\end{array}\right]=} & {\left[\begin{array}{cc}
0 & 1 \\
-\frac{1}{p_{1}\left(v_{m}\right) p_{2}\left(v_{m}\right)} & -\frac{p_{1}\left(v_{m}\right)+p_{2}\left(v_{m}\right)}{p_{1}\left(v_{m}\right) p_{2}\left(v_{m}\right)}
\end{array}\right]\left[\begin{array}{c}
v_{t} \\
\dot{v}_{t}
\end{array}\right]+} \\
& {\left[\begin{array}{c}
0 \\
\frac{k\left(v_{m}\right)}{p_{1}\left(v_{m}\right) p_{2}\left(v_{m}\right)}
\end{array}\right] e, \quad e \in N(0,1) }
\end{aligned}
$$

The parameters $k\left(v_{m}\right), p_{1}\left(v_{m}\right)$ and $p_{2}\left(v_{m}\right)$ are estimated by approximating wind power distribution and as it is indicated, they are dependent on the mean wind speed $\left(v_{m}\right)$.

\section{B. Nonlinear Model}

Blade element momentum(BEM) theory [11] is used to calculate aerodynamic torque and thrust on the wind turbine. This theory explains how torque and thrust are related to wind speed, blade pitch angle and rotational speed of the rotor with the following formulas:

$$
\begin{aligned}
Q_{r} & =\frac{1}{2} \frac{1}{\omega_{r}} \rho \pi R^{2} v_{e}^{3} C_{P}\left(\theta, \omega, v_{e}\right) \\
Q_{t} & =\frac{1}{2} \rho \pi R^{2} v_{e}^{2} C_{T}\left(\theta, \omega, v_{e}\right)
\end{aligned}
$$

In which $Q_{r}$ and $Q_{t}$ are aerodynamic torque and thrust, $\rho$ is air density, $\omega_{r}$ is rotor rotational speed, $v_{e}$ is effective wind speed, $C_{P}$ is the power coefficient and $C_{T}$ is the thrust force coefficient. For the sake of simplicity, instead of presenting these two coefficients as functions of three variables $\omega, v_{e}$ and $\theta$, they are presented as a function of two variables $\lambda$ and $\theta$ in which $\lambda=\frac{R \omega}{v_{e}}$ and it is called tip speed ratio. As we have not used individual pitch in this work absolute angular position of the rotor and generator are of no interest to us, therefore we use $\psi=\theta_{r}-\theta_{g}$ instead which is the drivetrain torsion. Having aerodynamic torque the whole system equation with 2 degrees of freedom becomes:

$$
\begin{gathered}
J_{r} \dot{\omega}_{r}=Q_{r}-c\left(\omega_{r}-\frac{\omega_{g}}{N_{g}}\right)-k \psi \\
\left(N_{g} J_{g}\right) \dot{\omega}_{g}=c\left(\omega_{r}-\frac{\omega_{g}}{N_{g}}\right)+k \psi-N_{g} Q_{g}
\end{gathered}
$$

In which $J_{r}$ and $J_{g}$ are rotor and generator moments of inertia, $\psi$ is the drivetrain torsion, $c$ and $k$ are the drivetrain damping and stiffness factors respectively lumped in the low speed side of the shaft. For numerical values of these parameters and other parameters given in this paper, we refer the reader to [12]. These equations give us a nonlinear model however our control design method is based on linear models, therefore we need to linearize the nonlinear model of the system which could be easily achieve using Taylor expansions around the operating points.

\section{Uncertain Model}

As it was mentioned, for control design we need to have a linear model of the system and the following model of the wind turbine is used:

$$
\left[\begin{array}{c}
\dot{x} \\
y_{\Delta} \\
y
\end{array}\right]=\left[\begin{array}{c|cc}
A & B_{1} & B_{2} \\
\hline C_{1} & D_{11} & D_{12} \\
C_{2} & D_{21} & D_{22}
\end{array}\right]\left[\begin{array}{c}
x \\
u_{\Delta} \\
u
\end{array}\right]
$$

In which states, inputs and outputs are:

$$
\begin{aligned}
& x=\left[\begin{array}{lllllll}
\omega_{r} & \omega_{g} & \psi & \theta & Q_{g} & v_{e} & \dot{v}_{e}
\end{array}\right]^{T} \\
& u=\left[\begin{array}{ll}
\theta_{\text {ref }} & Q_{\text {ref }}
\end{array}\right]^{T} \\
& y=\left[\begin{array}{lll}
\omega_{r} & \omega_{g} & P_{e}
\end{array}\right]^{T}
\end{aligned}
$$

$\omega_{r}$ is rotational speed of the rotor, $\omega_{g}$ is rotational speed of the generator, $\psi$ is drivetrain deflection, $\theta$ pitch of the blade, $Q_{g}$ is the generator reaction torque, $v_{e}$ and $\dot{v}_{e}$ are wind model states, $\theta_{\text {ref }}$ is the reference value for pitch angle and $Q_{\text {ref }}$ is the reference value for the generator reaction torque and $P_{e}$ is the electrical power. System equations are:

$$
\begin{aligned}
\dot{\omega}_{r} & =\frac{a-c}{J_{r}} \omega_{r}+\frac{c}{J_{r}} \omega_{g}-\frac{k}{J_{r}} \psi+b_{1} \theta+b_{2} v_{e} \\
\dot{\omega}_{g} & =\frac{c}{N_{g} J_{g}} \omega_{r}-\frac{c}{N_{g}^{2} J_{g}} \omega_{g}+\frac{k}{N_{g} J_{g}} \psi-\frac{Q_{g}}{J_{g}} \\
\dot{\psi} & =\omega_{r}-\frac{\omega_{g}}{N_{g}} \quad \dot{\theta}=-\frac{1}{\tau_{\theta}} \theta+\frac{1}{\tau_{\theta}} \theta_{r e f} \\
\dot{Q}_{g} & =-\frac{1}{\tau_{g}} Q_{g}+\frac{1}{\tau_{g}} Q_{r e f} \quad P_{e}=Q_{g_{0}} \omega_{g}+\omega_{g_{0}} Q_{g} \\
\ddot{v}_{e} & =-\frac{1}{p_{1} p_{2}} v_{e}-\frac{p_{1}+p_{2}}{p_{1} p_{2}} \dot{v}_{e}+\frac{k}{p_{1} p_{2}} e
\end{aligned}
$$

There are always discrepancies between real system and mathematical models, which lead to uncertain models. In this work, sources of uncertainties are taken to be:

- Uncertainty in the drivetrain stiffness and damping parameters.

- Uncertainty in the linearized model.

Uncertainty in the linearized model could be a result of approximate $C_{P}$ curve calculations, wrong wind speed estimation which results in picking the wrong operating point or aerodynamic changes due to blade flexibility or ice coatings on the blades. Multiplicative uncertainty is used to represent the uncertain parameters. The uncertainty matrix becomes:

$$
\left[\begin{array}{c}
u_{a} \\
u_{b_{1}} \\
u_{k} \\
u_{c}
\end{array}\right]=\left[\begin{array}{cccc}
\delta_{a} & 0 & 0 & 0 \\
0 & \delta_{b_{1}} & 0 & 0 \\
0 & 0 & \delta_{k} & 0 \\
0 & 0 & 0 & \delta_{c}
\end{array}\right]\left[\begin{array}{c}
y_{a} \\
y_{b_{1}} \\
y_{k} \\
y_{c}
\end{array}\right]
$$




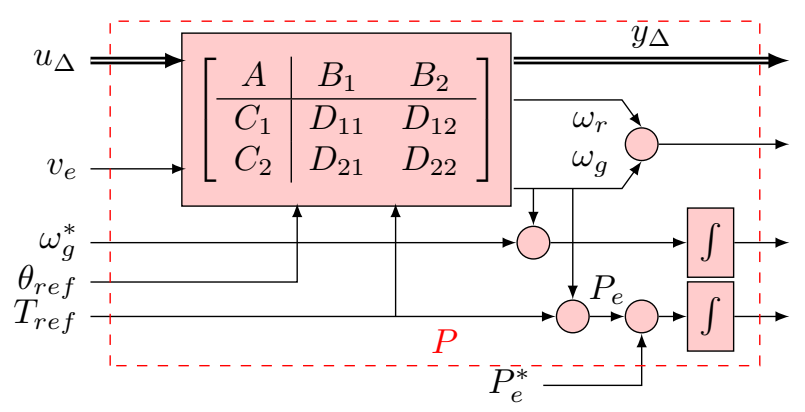

Fig. 2: System interconnections

$y_{\Delta}=\left[\begin{array}{llll}y_{a} & y_{b_{1}} & y_{k} & y_{c}\end{array}\right]^{T}$ is the uncertainty output, $y$ is the output, $u_{\Delta}=\left[\begin{array}{llll}u_{a} & u_{b_{1}} & u_{k} & u_{c}\end{array}\right]^{T}$ is the uncertainty input and $u$ is the input. Now having system equations, we can make the interconnection matrix $P$ (see figure 2):

$$
\left[\begin{array}{c}
y_{\Delta} \\
z \\
y
\end{array}\right]=P\left[\begin{array}{c}
u_{\Delta} \\
d \\
u
\end{array}\right]
$$

\section{Simulation Model}

The FAST (Fatigue, Aerodynamics, Structures, and Turbulence) code [13] is used as the simulation model and the $5 \mathrm{MW}$ reference wind turbine is used as the plant [12]. In the simulation model 10 degrees of freedom are enabled which are: generator, drivetrain torsion, 1 st and 2 nd tower fore-aft, 1st and 2nd tower side-side, 1st and 2nd blade flapwise, 1st blade edgewise degrees of freedom.

\section{E. Wind Speed Estimation}

Based on the nonlinear model given in (2) and the wind model given in (1) an extended Kalman filter is designed to estimate the effective wind speed. This wind speed is used to find the operating point of the wind turbine $\left(\theta^{*}, \lambda^{*}\right.$ and $C_{p}^{*}$ ) and linearize the nonlinear model.

\section{Controller Design}

\section{A. Control Objectives}

The most basic control objective of a wind turbine is to maximize power capture in the turbine life time, which this in turn means maximizing power captured from the wind and prolonging life time of the wind turbine by minimizing the fatigue loads. Generally maximizing power capture is considered in the partial load and minimizing fatigue loads is mainly considered above rated. As we are operating in the full load region in this work, we have considered the second objective. Control objectives are formulated in the form of weighting functions on input disturbances $(d)$ and exogenous outputs $(z)$. In order to avoid high frequency activity of the actuators, we have put high pass filter on control signals to punish high frequency actions. Also we have setup low pass filters to punish low frequency of the system outputs as their high frequency dynamics are outside of our actuator bandwidth and we can not control them

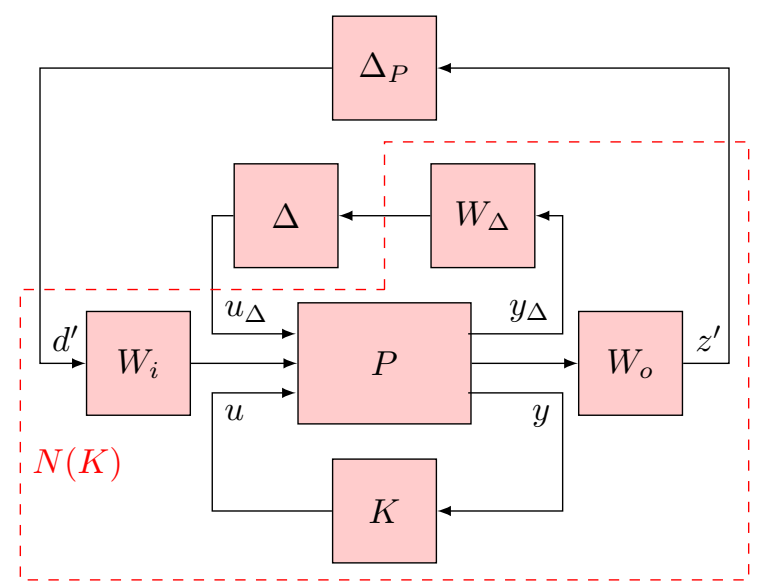

Fig. 3: System setup for robust performance problem

anyway. For regulating power and rotational speed, $P_{e}-P_{e}^{*}$ and $\int \omega_{g}-\omega_{g}^{*}$ and for minimizing fatigue loads on the drivetrain $\omega_{g}-N_{g} \omega_{r}$ are punished. The resulting controller is a dynamical system with measurements $y$ as its inputs and control signals $u$ as its outputs:

$$
\begin{aligned}
\dot{x}_{c} & =A_{c} x_{c}+B_{c} y \\
u & =C_{c} x_{c}
\end{aligned}
$$

\section{Robust Performance Problem}

\section{A. Theory}

Robust performance means that the performance objective is satisfied for all possible plants in the uncertainty set. The robust performance condition can be cast into a robust stability problem with an additional perturbation block that defines $H_{\infty}$ performance specifications [14]. The structured singular value $\mu$ is a very powerful tool for the analysis of robust performance with a given controller. However this is an analysis tool, in order to design a controller, we need a synthesis tool. A scaled version of the upper bound of $\mu$ is used for controller synthesis. The problem is formulated in the following form:

$$
\mu_{\Delta}(N(K)) \leq \min _{D \in \mathcal{D}} \sigma\left(D N(K) D^{-1}\right)
$$

Now, the synthesis problem can be cast into the following optimization problem in which one tries to to find a controller that minimizes the peak value over frequency of this upper bound:

$$
\min _{K \in \mathcal{K}}\left(\min _{D \in \mathcal{D}}\left\|D N(K) D^{-1}\right\|_{\infty}\right)
$$

This problem is solved by an iterative approach which is called $D K$-iteration. For detailed explanations on the method and notations the reader is referred to [14].

\section{B. Implementation}

We have used $\mu$-Synthesis toolbox [15] to implement the $D K$-Iteration algorithm. $W_{\Delta}$ is used to scale the $\Delta$ matrix. We have taken uncertainty of $10 \%$ of the nominal values for drivetrain stiffness and damping coefficients and $20 \%$ for 

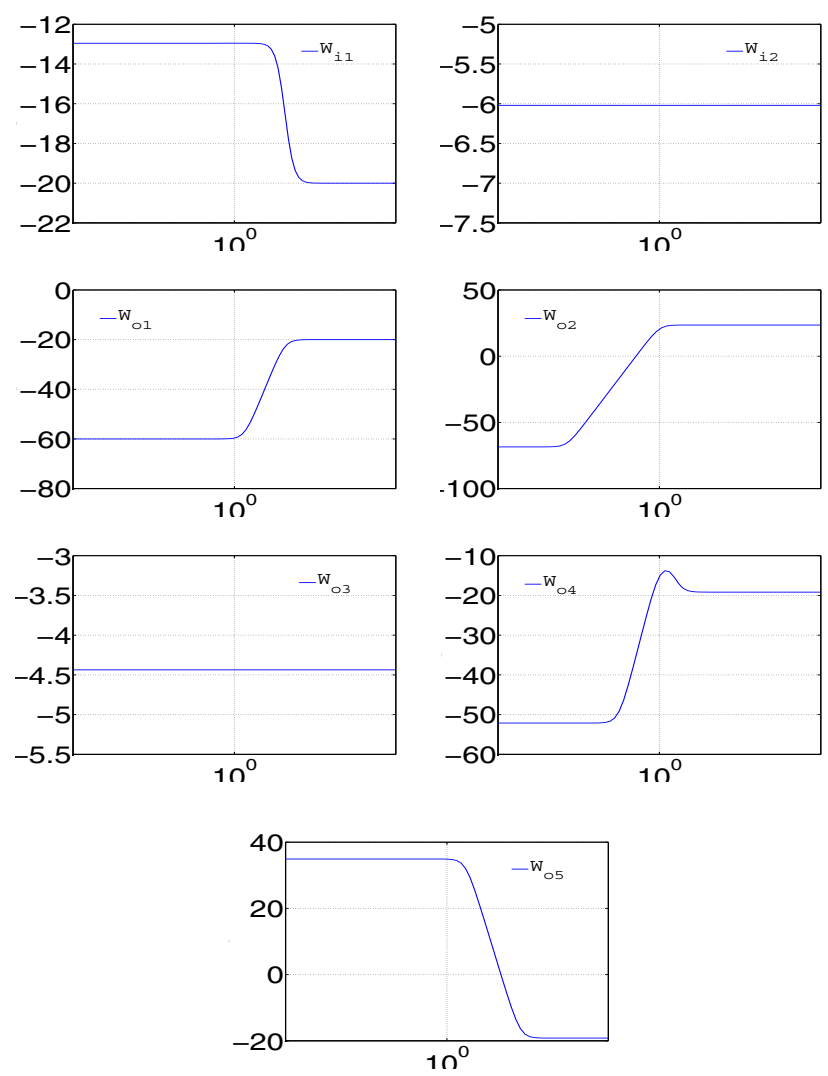

Fig. 4: Bode plots for performance specifications(y-axis is in $\mathrm{dB}$ and $\mathrm{x}$-axis is in $\mathrm{rad} / \mathrm{s}$ )

the linearization parameters therefore the weighting matrix becomes:

$$
W_{\Delta}=\operatorname{diag}(0.2,0.2,0.1,0.1)
$$

$\Delta_{P}$ (scaled by $W_{i}$ and $W_{o}$ matrices) defines performance of the system in the form of a complex perturbation matrix. $W_{i}$ and $W_{o}$ are frequency dependent weight matrices on disturbances and exogenous outputs respectively of the form:

$$
\begin{aligned}
& W_{o}=\operatorname{diag}\left(W_{o 1}, \ldots, W_{o 5}\right) \\
& W_{i}=\operatorname{diag}\left(W_{i 1}, W_{i 2}\right)
\end{aligned}
$$

Bode plots of the weighting functions are given in the figure 4. Figure 4 shows bode plots of weighting functions. Input disturbances $(d)$ to the system are:

$$
d=\left[\begin{array}{c}
v_{e} \\
\omega_{g}^{*}
\end{array}\right] \begin{aligned}
& \text { Wind Speed } \\
& \text { Rotor rotation reference }
\end{aligned}
$$

And exogenous outputs $(z)$ are:

$$
z=\left[\begin{array}{c}
\theta_{\text {ref }} \\
Q_{r e f} \\
\omega_{r}^{*}-\frac{\omega_{g}}{N_{g}} \\
\int \omega_{g}^{*}-\omega_{g} \\
\int P_{e}^{*}-P_{e}
\end{array}\right] \begin{aligned}
& \text { Pitch reference } \\
& \text { Generator reaction torque reference } \\
& \text { Deflection of the drivetrain } \\
& \text { Integral on rotational on geed error }
\end{aligned}
$$

These weightings are used to specify performance of the system. As we have parametric uncertainties in the plant and

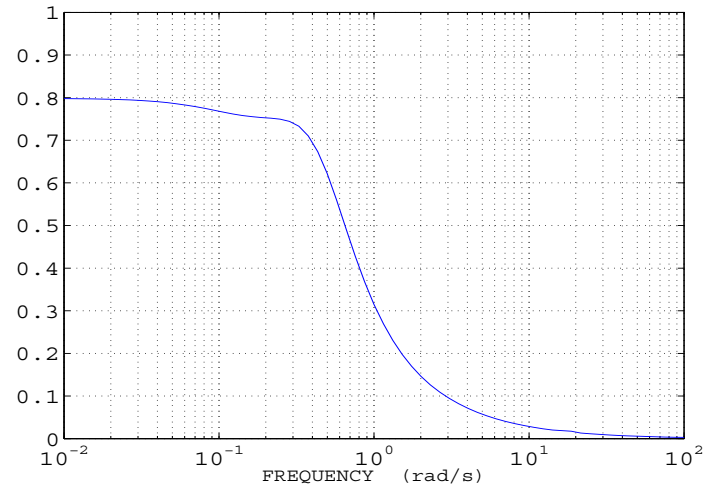

Fig. 5: Closed loop mixed $\mu$

\begin{tabular}{lccc} 
Iteration number & 1 & 2 & 3 \\
\hline Controller Order & 19 & 19 & 19 \\
$\gamma$ Acheived & 9682006.84 & 45.289 & 7.347 \\
Peak $\mu$-Value & 2482.23 & 0.865 & 0.808
\end{tabular}

TABLE I: $D K$-iteration summery

complex perturbation for performancs, mixed $\mu$ is used to design the controller. The resulting mixed- $\mu$ is given in figure 5 and the iteration summery is given in the table I. The obtained controller is of the order 19, and has maximum gain of $15.86 \mathrm{~dB}$. As high order controllers are problematic in the real implementations, we have used balanced order reduction [16] to reduce its order to 10. Hankel singular values of the controller are shown in figure 6 and the jump from order 10 to 11 is found a reasonable place for controller order reduction.

\section{Simulation Results}

In this section simulation results for the obtained controller are presented. The controller is implemented in MATLAB and tested on full complexity FAST model of the reference wind turbine [12]. As it is mentioned in section II-E we have augmented model of wind turbine with a stochastic wind model, however in order to make evaluation of the controller on nominal and worst case, we have used simulations with step changes in the wind speed.

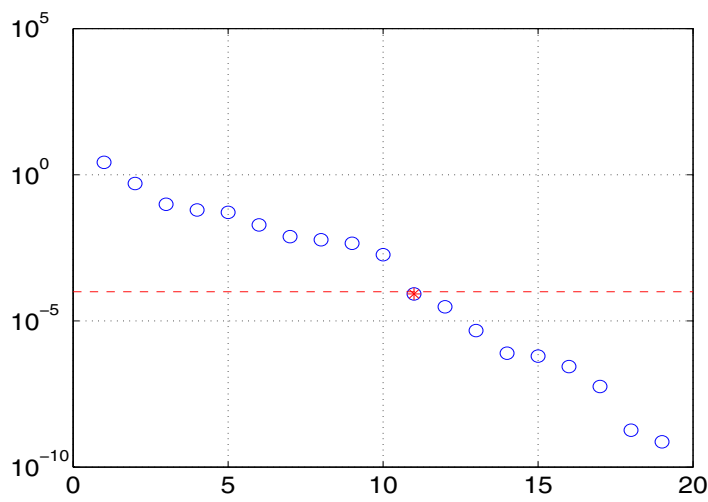

Fig. 6: Hankel singular values of the controller 


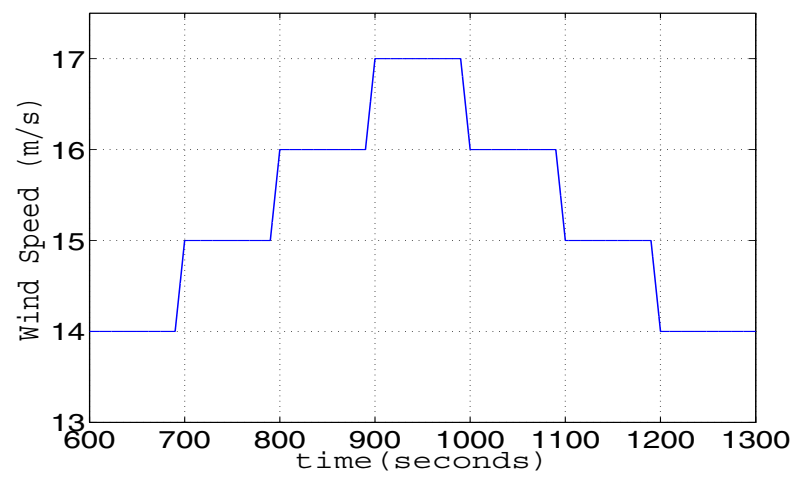

Fig. 7: Wind speed

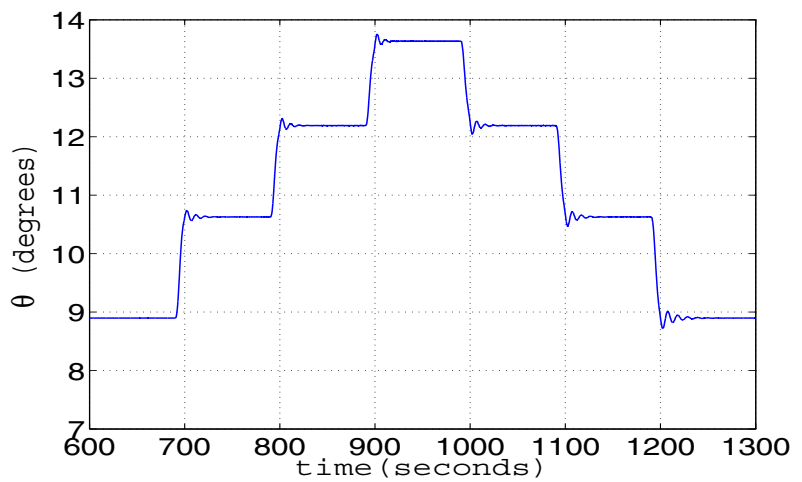

Fig. 8: Blade-pitch reference

\section{A. Robust performance simulations}

In this section simulation results of a step change in wind speed is presented. Control inputs which are pitch reference $\theta_{\text {ref }}$ and generator reaction torque reference $T_{r e f}$ along with system outputs which are rotor rotational speed $\omega_{r}$ and electrical power $P_{e}$ are plotted in figues 7-11.

\section{B. Simulation for the worst case}

In this section worst case scenarios, in which all the uncertainties are taken to be the maximum values, are presented. To do so, wind speed is taken to be $2 \mathrm{~m} / \mathrm{s}$ away from the linearization point and nominal values of the drivetrain stiffness and damping are replaced by the following values:

$$
\begin{aligned}
k=\bar{k}\left(1+P_{k} \delta_{k}\right) & \text { for } \delta_{k}= \pm 1 \& P_{k}=0.1 \\
c=\bar{c}\left(1+P_{c} \delta_{c}\right) & \text { for } \delta_{c}= \pm 1 \& P_{c}=0.1
\end{aligned}
$$

As it is seen in figures 12 and 13 , in the worst cases the system becomes oscillatory but it maintains a reasonable performance.

\section{CONCLUSION}

In this paper we solved the problem of robust control of a wind turbine using $D K$-iteration technique. The controller is designed for the full load region, and an extension of this work would be to solve the problem for partial load too. Parametric uncertainty is considered in the uncertain model and then we have used $\mu$-synthesis method to design the

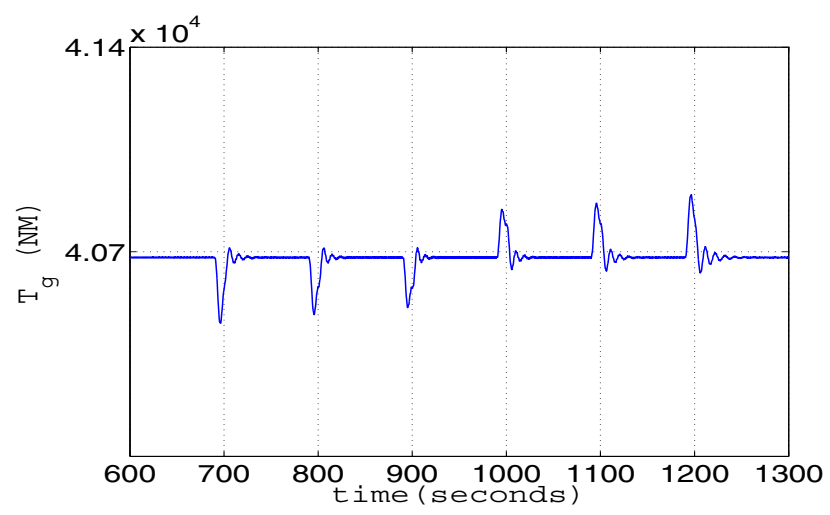

Fig. 9: Generator-torque reference

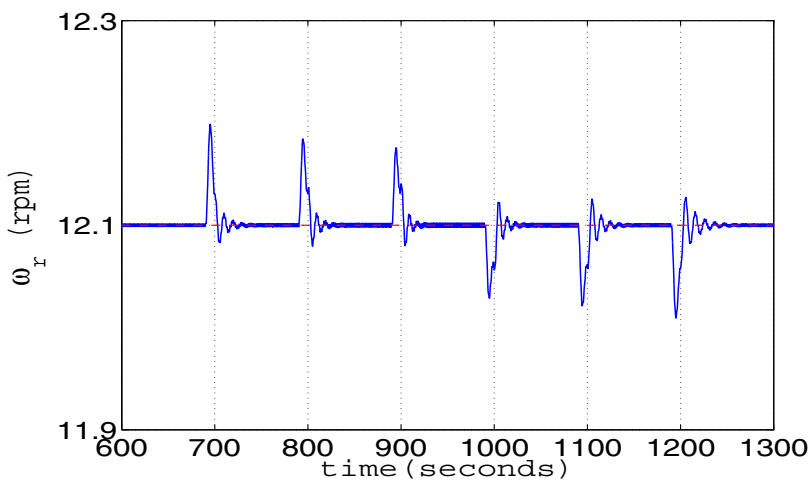

Fig. 10: Rotor rotational speed $\left(\omega_{r}\right)$

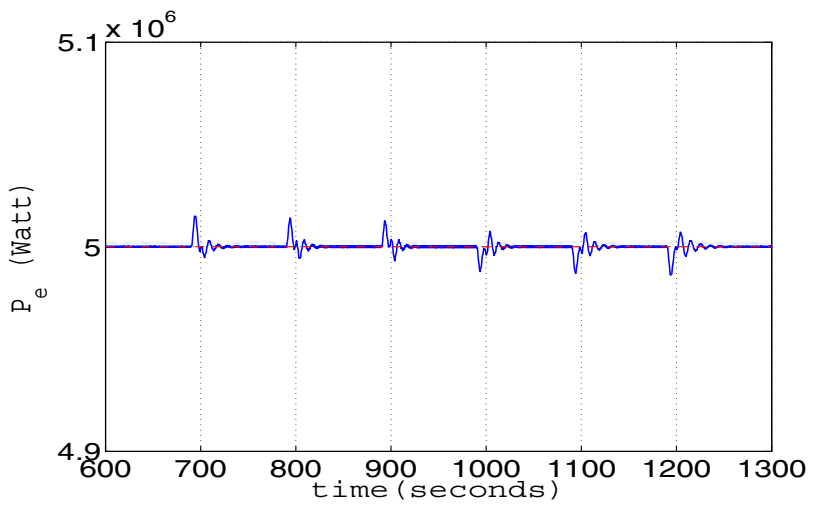

Fig. 11: Electrical power

controller. The full model with augmented wind model is of the order 8 and the resulting controller is of the order 19 , however balanced truncation model order reduction is used to reduce order of the controller to 10 . The final controller is implemented on a FAST simulation model with 10 degrees of freedom and simulations with wind speed step changes are done for nominal plant and worst case plant. The results suggest that the controller can handle nominal case pretty well and the worst case with a little loss of performance. 


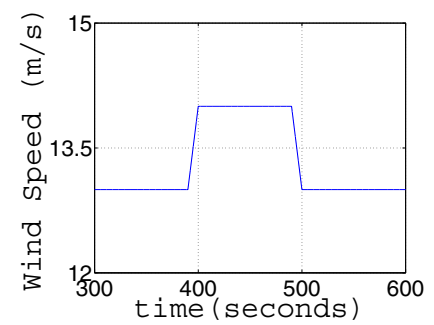

(a) Wind speed

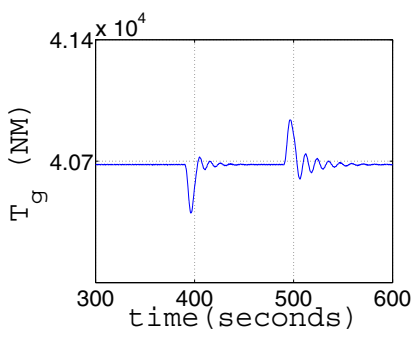

(c) Generator reaction torque reference

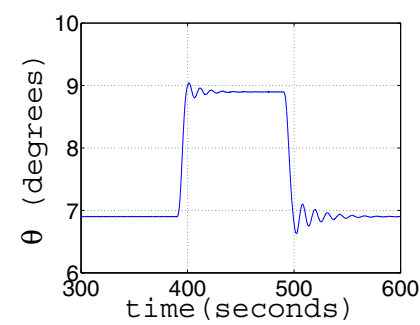

(b) Pitch reference

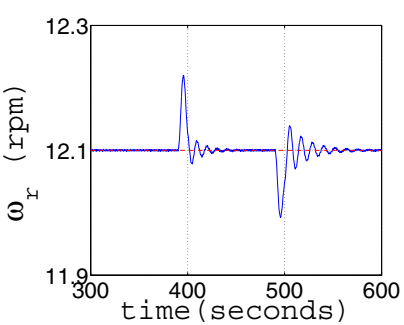

(d) Rotor rotational speed

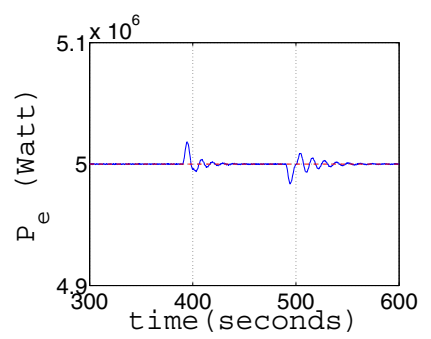

(e) Electrical power

Fig. 12: Worst case scenario with $+2 \mathrm{~m} / \mathrm{s}$ wind speed estimation error

\section{REFERENCES}

[1] W.E. Leithead and Bill Connor. Control of variable speed wind turbines: Design task. Int J Control, 73(13):1189-1212, 2000.

[2] J.H. Laks, L.Y. Pao, and A.D. Wright. Control of wind turbines: Past, present, and future. Proceedings of the American Control Conference, pages 2096-2103, 2009.

[3] Fernando D. Bianchi, Hernan De Battista, and Ricardo J. Mantz. Wind Turbine Control Systems: Principles, Modelling and Gain Scheduling Design. Springer, 2006.

[4] Johnson and Fingersh. Adaptive pitch control of variable-speed wind turbines. J. Sol. Energy Eng. (USA), 130(3):031012-1-7, 2008.

[5] M. Geyler and P. Caselitz. Robust multivariable pitch control design for load reduction on large wind turbines. J. Sol. Energy Eng. Trans.ASME J SOL ENERG J SOL ENERG-T ASME J SOL ENERGY ENG Journal of solar energy engineering, 130(3):-, 2008.

[6] Sven Creutz Thomsen. Nonlinear control of a wind turbine. Master's thesis, Technical University of Denmark, Informatics and Mathematical Modelling, 2006.

[7] Kasper Zinck Østergaard. Robust, Gain-Scheduled Control of Wind Turbines. PhD thesis, Automation and Control Department of Electronic Systems, Aalborg University, 2008.

[8] Lars Christian Henriksen. Model predictive control of a wind turbine. Master's thesis, Technical University of Denmark, Informatics and Mathematical Modelling, 2007.

[9] M. Harris, M. Hand, and A. Wright. Lidar for turbine control. Technical report, National Renewable Energy Laboratory, 2006.

[10] Peter Bjørn Andersen. Advanced Load Alleviation for Wind Turbines

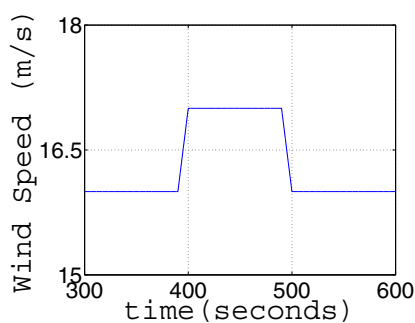

(a) Wind speed

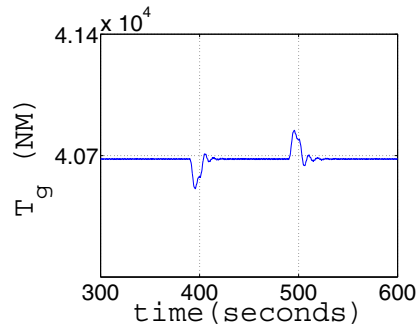

(c) Generator reaction torque reference

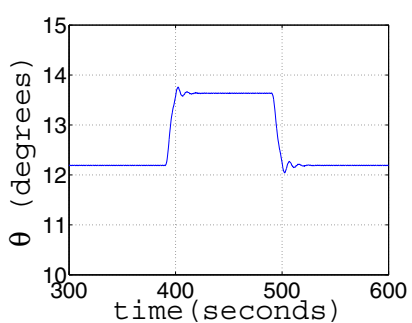

(b) Pitch reference

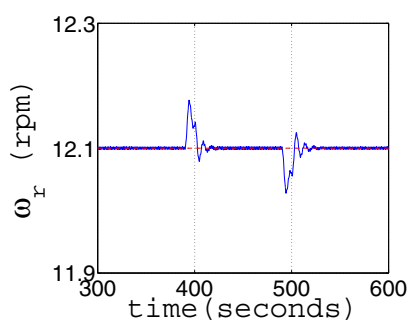

(d) Rotor rotational speed

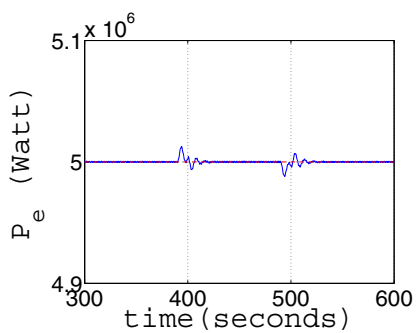

(e) Electrical power

Fig. 13: Worst case scenario with $-2 \mathrm{~m} / \mathrm{s}$ wind speed estimation error

using Adaptive Trailing Edge Flaps: Sensoring and Control. $\mathrm{PhD}$ thesis, Technical University of Denmark, 2010.

[11] Martin O. L. Hansen. Aerodynamics of Wind Turbines. Earthscan, 2008

[12] J. Jonkman, S. Butterfield, W. Musial, and G. Scott. Definition of a $5 \mathrm{MW}$ reference wind turbine for offshore system development. Technical report, National Renewable Energy Laboratory, 2009.

[13] Jason M. Jonkman and Marshall L. Buhl Jr. Fast users guide. Technical Report NREL/EL-500-38230, National Renewable Energy Laboratory, August 2005.

[14] Sigurd Skogestad and Ian Postlethwaite. Multivariable Feedback Control Analysis and design. JOHN WILEY \& SONS, Second Edition, 2001

[15] The MathWorks, Inc. $\mu$-Analysis and Synthesis Toolbox, June 1998.

[16] A. Varga. Balancing free square-root algorithm for computing singular perturbation approximations. Proc IEEE Conf Decis Control, 2:10621065,1991 